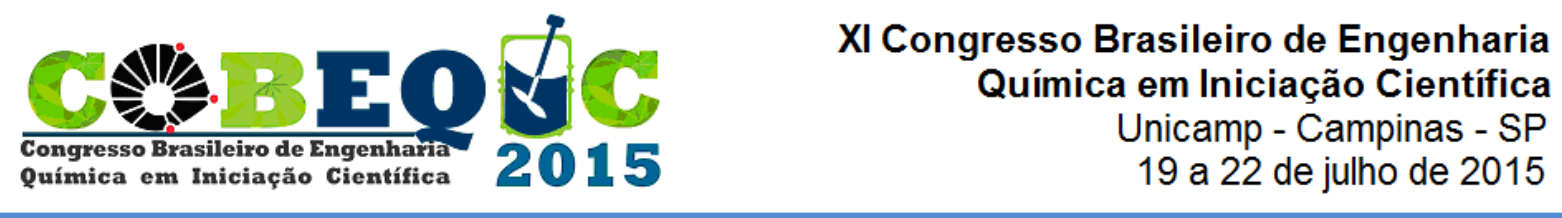

\title{
SIMULAÇÃO DO PROCESSO DE DESASFALTAÇÃO A PROPANO
}

\author{
R. A. de SOUZA ${ }^{1}$, A. A. de OLIVEIRA ${ }^{1}$, V. O. CARDENAS C. ${ }^{2}$ \\ ${ }^{1}$ Universidade Metodista de Piracicaba, Faculdade de Engenharia, Arquitetura e Urbanismo \\ ${ }^{2}$ Universidade Federal de São Paulo, Departamento de Engenharia Química \\ E-mail para contato: roniel.souza@gmail.com
}

\begin{abstract}
RESUMO - O processo de desasfaltação à propano líquido permite a extração e recuperação de frações oleosas que podem ser utilizadas na produção de compostos mais nobres. A carga que alimenta a unidade de desasfaltação é conhecida como resíduo de vácuo (RV), rica em compostos asfaltênicos, na qual ainda existem compostos oleosos. O solvente usado na extração é o propano ou uma mistura de hidrocarbonetos de baixa massa molar (propano e butano). Dessa maneira a unidade de desasfaltação tem como finalidade recuperar de um resíduo uma fração mais leve (óleo desasfaltado - ODES), separando-a de uma fração mais pesada (resíduo asfáltico - RASF). Sendo assim, o processo estudado visa obter dados de processo através do simulador comercial Aspen Plus ${ }^{\circledR}$. Variáveis como temperatura, pressão e relação óleo/solvente serão estudadas, a fim de encontrar a melhor configuração para o extrator. O modelo termodinâmico usado é o PSRK (PredictiveSoave-Redlich-Kwong) o qual permite trabalhar em condições elevadas de temperatura e pressão, assim como, usar componentes complexos como os resíduos de petróleo. Os resultados obtidos mostram que o modelo termodinâmico comportou-se de maneira eficaz, conseguiu-se uma separação de componentes leves (ODES) no topo da extratora e componentes pesados no fundo (RASF).
\end{abstract}

\section{INTRODUÇÃO}

Antes da descoberto do pré-sal,as refinarias encontravm dificldades no processamento dos óleo pesados, comumente encontrados no Brasil. Sendo assim, a indústria de petróleo foram forçadas a pesquisar e desenvolver novos processos de refino aplicáveis a óleos crus e resíduos cada vez mais pesados, objetivando-se a obtenção dos produtos finais de refino com maior qualidade e obedecendo as especificações da legislação vigente. Durante as últimas duas décadas, a qualidade média do petróleo derivado das refinarias tem diminuído aproximadamente 2 pontos na escala API, acompanhado de um aumento de sólidos inorgânicos, metais pesados e heteroátomos (Speight, 1999).

Algumas refinarias enfrentam desafios ao processar óleos pesados (baixo Grau API) devido a suas características serem diferentes dos óleos comumente processados (óleo leves, elevado Grau API). O processo de desasfaltação de resíduo de vácuo ou atmosférico se mostra uma alternativa eficaz para a separação do asfalto do óleo lubrificante em comparação com o processo tradicional de desasfaltação através de extração líquido-líquido utilizando éter de petróleo como solvente. 
Em 1936, Wilson et al. desenvolveram um processo de separação baseado no equilíbrio de fases que se tornou a base para o processo de desasfaltação a propano, ainda hoje em uso no refino de óleos lubrificantes. Embora o processo não seja de extração supercrítica conceitualmente falando, ele faz uso da mudança do poder de solvência de um líquido nas vizinhanças de seu ponto crítico. Uma vez que as características do propano como solvente podem ser drasticamente alteradas no espaço pressão-temperatura, este solvente pode ser usado seletivamente para separar uma mistura de óleo lubrificante em parafina, asfalto, produtos pesados, naftênicos, corpos coloridos e no produto desejado (óleo lubrificante leve).

O objetivo desse trabalho é simular um processo de desasfaltação utilizando propano como solvente extrator, variando as condições de pressão e temperatura de modo a explorar as propriedades do propano na fase líquida. Para isso, simulações foram realizadas com o auxílio do software Aspen Plus ${ }^{\circledR}$ de modo a caracterizar uma "planta virtual" de desasfaltação de resíduo de vácuo produzindo óleo desasfaltado (ODES) e Asfalto.

\section{MATERIAIS E MÉTODOS}

\subsection{Manipulação da amostra utilizada}

Utilizou-se para o desenvolvimento do trabalho o software de simulação de processos ASPEN PLUS ${ }^{\circledR}$ 7.3; o modelo termodinâmico PSRK (Predictive Soave-Redlich-Kwong) foi escolhido devido à flexibilidade de predizer as propriedades físicas dos componentes estudados.

A Tabela 1 apresenta os pontos de ebulição em função da porcentagem de destilado do petróleo estudado (grau API 12,3) (Henriques, 2011). A partir destes dados foi possível gerar a curva PEV do petróleo a ser estudado, a qual é observada na Figura 1.

\begin{tabular}{|c|c|}
\hline $\begin{array}{l}\text { Temperatura de } \\
\text { Ebulição }\left({ }^{\circ} \mathrm{C}\right)\end{array}$ & $\begin{array}{l}\% \text { de destilado } \\
\text { volumétrico }\end{array}$ \\
\hline 239,8 & 5 \\
\hline 262 & 10 \\
\hline 354,8 & 20 \\
\hline 395,1 & 30 \\
\hline 465,5 & 40 \\
\hline 506 & 50 \\
\hline 549 & 60 \\
\hline 592,1 & 70 \\
\hline 688,1 & 85 \\
\hline 718 & 90 \\
\hline
\end{tabular}


Figura 1 - Curva PEV do Petróleo.

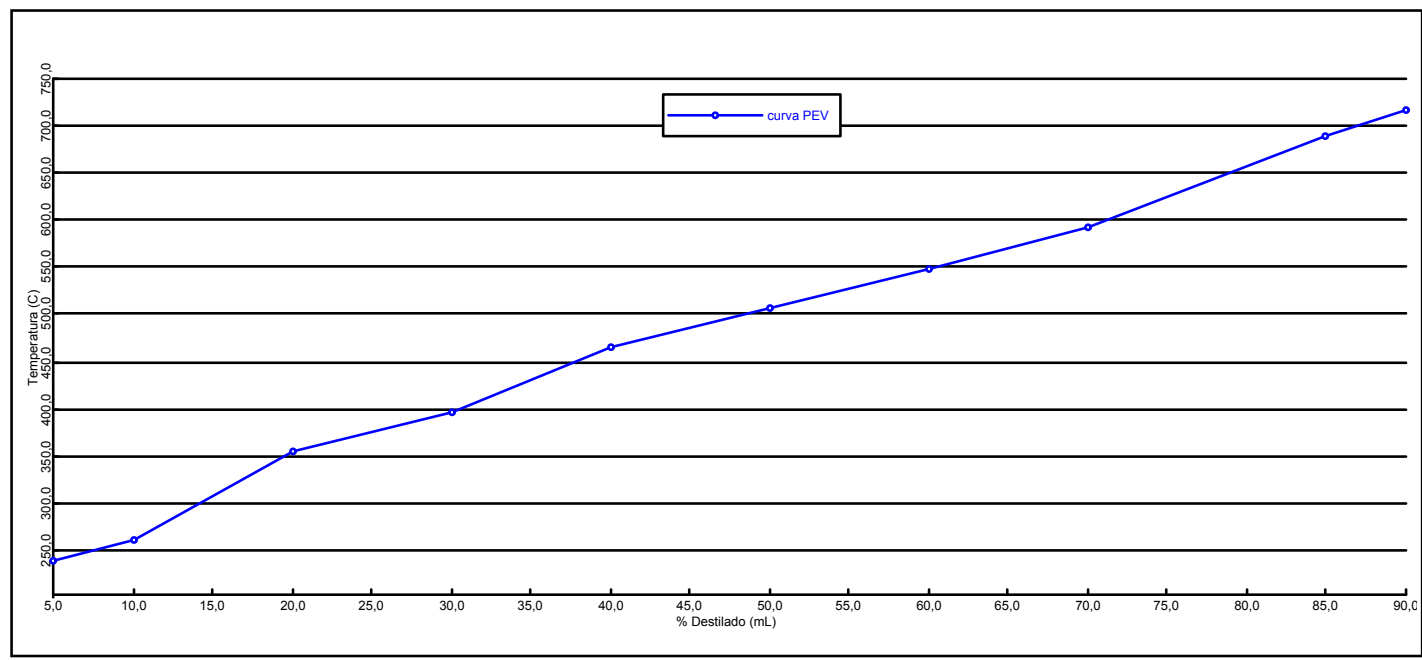

A partir da curva PEV da amostra, foi possível gerar no simulador os pseudocomponentes do petróleo. O simulador utiliza as correlações de Riazi e Daubert (1980) para cálculo das propriedades críticas dos pseudocomponentes.

A caracterização do resíduo de petróleo ("Crude Assay") foi realizada a partir da definição dos pseudocomponentes e suas propriedades.

\subsection{Planta virtual}

Considerou-se o processo em estado estacionário, no qual espera-se a obtenção de duas correntes de saída, ODES e RASF, que podem ser observadas no fluxograma de processos (Figura 2).

Figura 2 - Fluxograma de processo da planta virtual de desasfaltação.

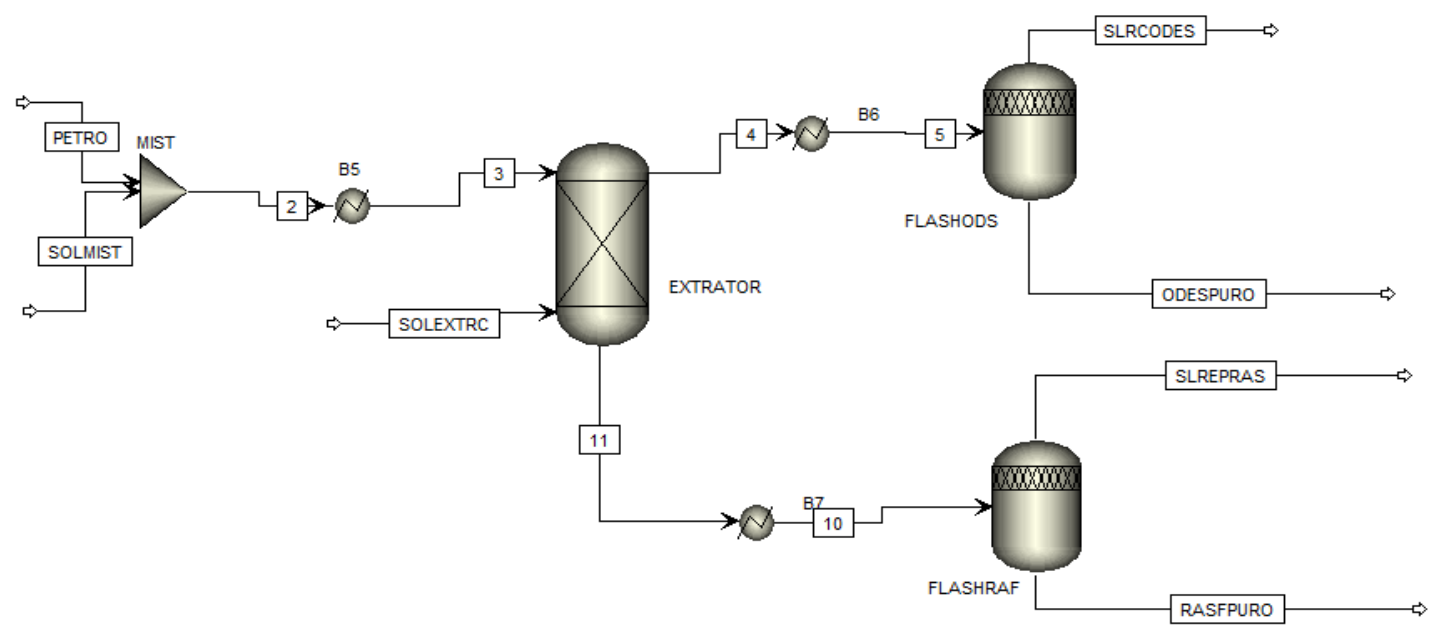

A Tabela 2 traz os principais parâmetros operacionais ajustados para a coluna extratora de desasfaltação. 
Tabela 2 - Principais parâmetros operacionais da coluna de desasfaltação

\begin{tabular}{cc}
\hline Parâmetros & Descrição \\
\hline $\mathrm{N}^{\mathrm{o}}$ de estágios ideais $(\mathrm{N})$ & 10 \\
Tipo de operação & Contra-corrente \\
Troca térmica & Adiabático \\
Pressão de operação & $36 \mathrm{bar}$ \\
Temperatura do topo & $75,42^{\circ} \mathrm{C}$ \\
Temperatura do fundo & $71,01^{\circ} \mathrm{C}$ \\
Vazão de resíduo & $250 \mathrm{~kg} / \mathrm{h}$ \\
Vazão de solvente & $600 \mathrm{Kg} / \mathrm{h}$ \\
\hline
\end{tabular}

Após a desasfaltação, as correntes de topo e fundo do extrator precisam passar por processos de troca térmica e descompressão para poder obter o produto final livre de solvente.

\section{RESULTADOS}

A seguir são apresentados alguns resultados obtidos nas simulações na forma de figuras e tabelas. A Figura 3 apresenta a curva PEV das respectivas correntes de saída (ODES e RASF).

Figura 3 - PEV das correntes de saída ODES e RASF.

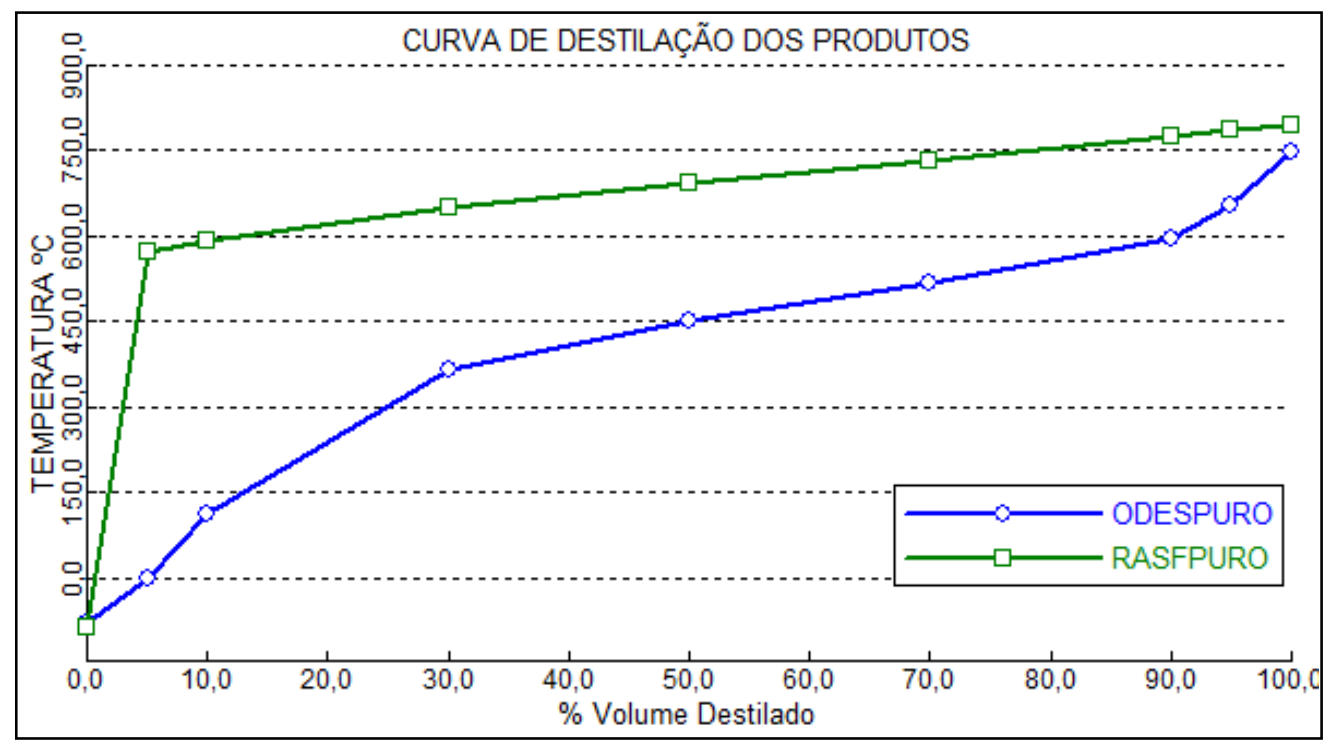

Na Figura 4 observa-se que houve a geração de duas correntes com pontos de ebulição diferentes. A PEV do ODES encontra-se na parte inferior, caracterizando uma corrente com compostos leves em relação a curva PEV do RASF, que aprestam pontos de ebulição mais elevadas.

A Figura 4 apresenta a obtenção de ODES em relação vazão de solvente. 
Figura 4 - Obtenção de ODES com o aumento da vazão de solvente.

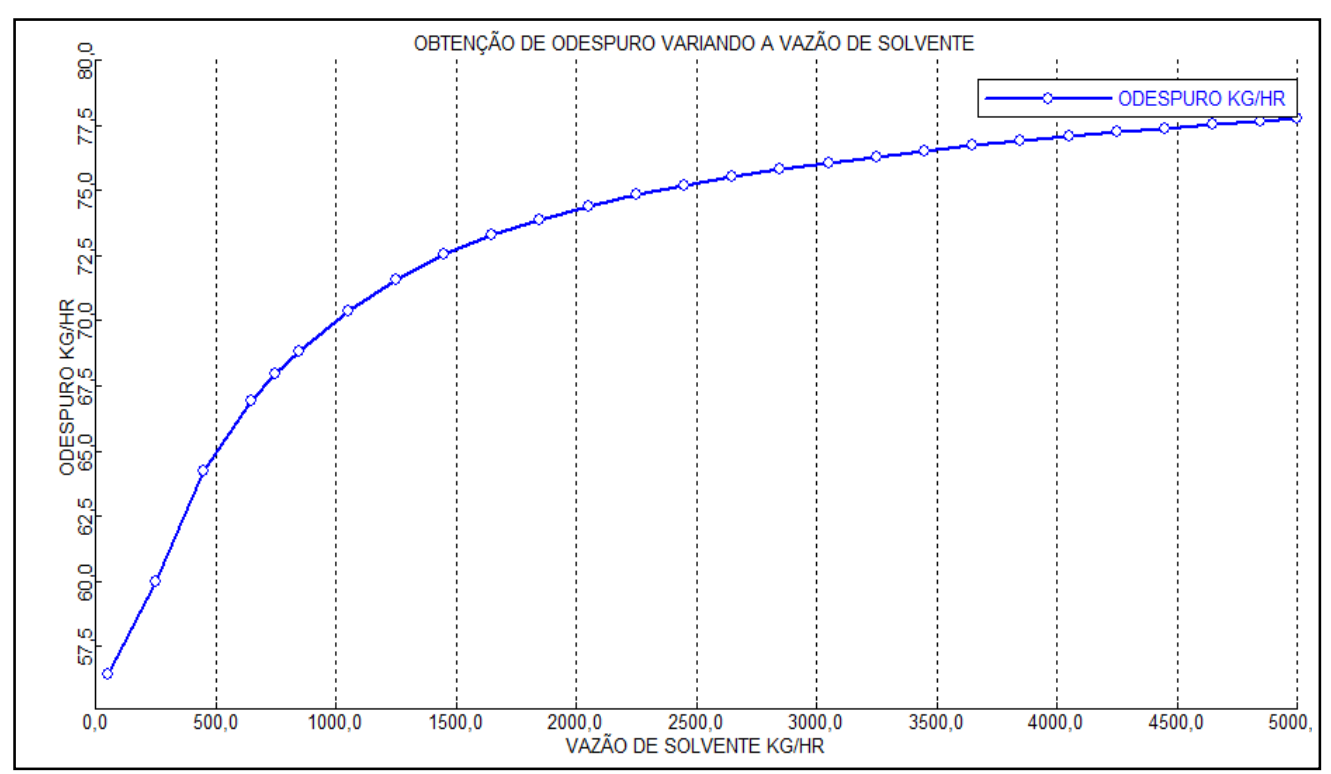

A Figura 4 mostra a influência da vazão do solvente em relação a obtenção de ODES, percebe-se que conforme aumenta vazão de solvente a extração de ODES é maior até alcançar aproximadamente $3000 \mathrm{~kg} / \mathrm{h}$. Cabe ressaltar que esta relação depende do petróleo ou resíduo utilizado.

As Tabelas 3 e 4 apresentam respectivamente alguns resultados obtidos, comparando as duas correntes de saída, bem como o rendimento mássico da extração.

Tabela 3 - Caracterização das correntes principais de processo (Produtos)

\begin{tabular}{ccc}
\hline Corrente & ODESPURO & RASFPURO \\
\hline Vazão mássica (Kg/h) & 125,9 & 82 \\
Massa molar médio (MW) & 230,9 & 426,4 \\
`API & 24,0 & 6,4 \\
Viscosidade (cP) & 0,9 & 7,1 \\
\hline
\end{tabular}

Na Tabela 4, observam-se os rendimentos em massa para cada corrente de saída do processo.

Tabela 4 - Rendimentos finais do processo

\begin{tabular}{cc}
\hline Parâmetros & Rendimento em massa (\%) \\
\hline Rendimento ODES & 62,95 \\
Rendimento Asfalto & 41 \\
\% solvente recuperado & 0,988 \\
\hline
\end{tabular}




\section{Pureza solvente recuperado $\quad 0,999$}

\section{CONCLUSÕES}

Conclui-se que o processo de desasfaltação de resíduos pesados usando propano como solvente é eficiente na remoção de asfalto e componentes pesados de um petróleo pesado ou resíduo de vácuo para produção de óleo desasfaltado. O propano pode ser avaliado como um ótimo solvente a ser usado na desasfaltação já que suas propriedades de solubilização e seletividade podem ser vastamente exploradas de acordo com seu estado físico, trabalhandose com propano líquido, quase-crítico e supercrítico durante o processo.

\section{REFERÊNCIAS}

HENRIQUES, B. C. “Caracterização Prévia de Petróleo com vistas à Otimização de Processos”. Tese de Doutorado, FEQ/Unicamp, Campinas, SP, 2011.

RIAZI, M. R.; DAUBERT, T. E. Simplify Property Predictions. Hydrocarbon Processing, v. 59, n.3, p.115-116, 1980 .

SPEIGHT, J. G., The chemistry and technology of petroleum. 1999, New York.: Marcel Dekker. 12

WILSON, R. E.; KEITH, P. C.; HAYLETT, R. E. Liquid-propane use in dewaxing, desasphalting, and refining heavy oils. Ind. Eng. Chem., v.28, p.1065-1078, 1936. 